\title{
Catheter palliation or early surgery for tetralogy of Fallot: Options when timing is less than ideal
}

\author{
James M. Hammel, MD
}

From the Department of Cardiothoracic Surgery, Children's Hospital and Medical Center, Omaha, Neb. Disclosures: Author has nothing to disclose with regard to commercial support.

Received for publication July 24, 2017; accepted for publication July 25, 2017; available ahead of print Sept 8, 2017.

Address for reprints: James M. Hammel, MD, Cardiothoracic Surgery, Children's Hospital and Medical Center, 8200 Dodge, Omaha, NE 68114 (E-mail: jhammel@chsomaha.org).

J Thorac Cardiovasc Surg 2017;154:1690-1

0022-5223/\$36.00

Copyright (c) 2017 by The American Association for Thoracic Surgery

http://dx.doi.org/10.1016/j.jtevs.2017.07.044

As an inherently balanced lesion, tetralogy of Fallot presents the clinician with options for the timing and nature of repair. The natural history generally includes good early growth and development, but it also includes progressive underdevelopment of the right ventricular outflow tract structures relative to somatic growth, producing increasingly severe baseline pulmonary undercirculation and cyanosis. In some patients, there are episodes of hypercyanosis, which if present tend to increase in frequency and severity and can be injurious or lethal. In an ideal world, definitive intervention would occur in a single surgical event; would optimize the structure, function, and growth potential of the pulmonary valve; and would take place at an age at which speedy and uneventful recovery is very likely. Surgical management of tetralogy of Fallot has been refined to the extent that in most patients, all these objectives can be met at once. In the real world, however, infants with tetralogy sometimes have problematic arterial oxygen desaturation when they are still smaller than is comfortable, or when they are ill for other reasons. In this issue of the Journal, Wilder and associates ${ }^{1}$ help us to consider what to do in these cases.

Having years ago abandoned systemic to pulmonary shunt creation, Wilder and associates ${ }^{1}$ here inform the reader about the outcomes of early definitive repair and catheter-based palliation. Because death occurred infrequently in all groups, they confine their assessment of outcome to the incidence and timing of reintervention, leaving the length of recovery, cost, and other considerations for other analyses. Even so, their observations are informative. Catheter-based palliation is possible, whether by dilation or stenting of the right ventricular outflow tract or stent dilation of a still-patent ductus arteriosus, although with a higher incidence of catheter reintervention than if repair had been achieved in a single step. Early definitive surgery, for its part, is achieved with a likelihood of reoperation that is greater than that in patients operated on when older, but not drastically so.

This work of Wilder and associates ${ }^{1}$ will be of interest to the clinician, but important questions remain. First,

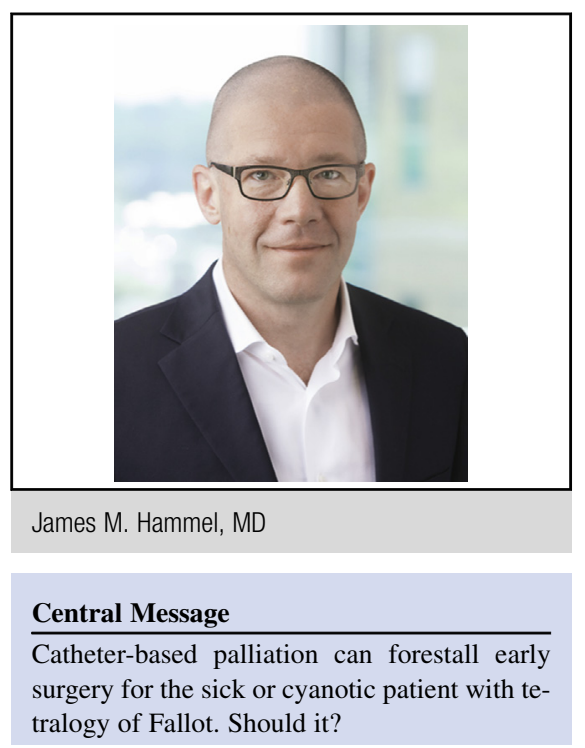

See Article page 1692. although death may not be analytically accessible in their current data set, 1 death among 28 patients with catheter palliation is actually a very large number relative to the almost uniform survival achieved after surgery in older patients. Second, patients with catheter palliation required much longer operations for complete repair and usually ended up with a transannular patch anyway. Whatever potential there may be to preserve the pulmonary valve, it must be less after there has been a stent placed through it. And whereas surgeons typically confine their myectomy to the infundibular free wall, a stent will be incorporated into all directions equally, including in proximity to the left coronary artery. Catheter-based initial palliation presents a favorable option for some small group of patients with serious contraindications to surgery, but it will probably not contribute positively to management in the majority of cases.

Early surgery, on the other hand, shows itself well in the study of Wilder and associates. ${ }^{1}$ Definitive surgery in younger infants was completed in identical time to that in larger patients, suggesting that the operation was not more difficult. A transannular incision was only slightly more common, a predictable finding in a group with more severe pulmonary hypoplasia. Other outcomes, such as the increased rate of conduit placement-a distinctly suboptimal outcome-are not well explained, because a transannular patch is possible in even the smallest right 
ventricular outflow tract. The reader's understanding would have been improved by a more granular explanation of the reasons for reoperation, whether progressive obstruction or the consequences of pulmonary insufficiency. In any case, history suggests that with time surgeons will likely perform the more complex pulmonary valve-sparing or reconstruction operations in patients of all sizes, including the very small. ${ }^{2,3}$ Timing of definitive repair will be dictated by optimal physiologic status, which for tetralogy of Fallot probably means as soon as baseline arterial oxygen saturation falls below $90 \%$ or as soon as a single hypercyanotic spell occurs.

How best to treat the small or ill infant with tetralogy of Fallot and problematic cyanosis or hypercyanotic spells?
These are separate questions, although they are considered together in the report of Wilder and associates. ${ }^{1}$ The infant with serious comorbidities that preclude safe surgery will benefit from catheter palliation. The small infant, on the other hand, may just as well get on with repair.

\section{References}

1. Wilder TJ, Van Arsdell GS, Benson L, Pham-Hung E, Gritti M, Page A, et al. Young infants with severe tetralogy of Fallot: early primary surgery versus transcatheter palliation. J Thorac Cardiovasc Surg. 2017;154: 1692-700.e9.

2. Sung SC, Kim S, Woo JS, Lee YS. Pulmonic valve annular enlargement with valve repair in tetralogy of Fallot. Ann Thorac Surg. 2003;75:303-5.

3. Vida VL, Zuchetta F, Stellin G. Pulmonary valve-sparing techniques during repair of tetralogy of Fallot: the delamination plasty. J Thorac Cardiovasc Surg. 2016; 151:1757-8. 